\title{
Reduction of Dexamethasone-Induced Oxidative Stress and Lipid Peroxidation in Laying Hens by Dietary Vitamin E Supplementation
}

\author{
Y. Eid ${ }^{1}$, T. Ebeid ${ }^{1}$. M. Moawad ${ }^{2}$ and M. El-Habbak ${ }^{1}$ \\ ${ }^{1}$ Department of Poultry Production, Faculty of Agriculture, Kafrelsheikh University, 33516 \\ Kafr El-Sheikh, Egypt; ${ }^{2}$ Animal Production Research Institute, Agricultural, Research \\ Center, Ministry of Agriculture, Giza, Egypt
}

\begin{abstract}
The objective of the present study is to research the effect of dietary vitamin E (Vit E) on laying performance, lipid peroxidation and antioxidative status in laying hens under experimentally induced oxidative stress conditions via Dexamethasone (DEX) administration. A total of 60 Egyptian local strain (Gimmizah) laying hens at 36 weeks of age were housed in individual cages in an open-sided building under a $16 \mathrm{hr}$ light: $8 \mathrm{hr}$ dark lighting schedule. The birds were randomly divided into four experimentally treatments: DEX (4 mg/hen/day); Vit. E $(200 \mathrm{mg} / \mathrm{kg}$ diet); DEX+Vit. E (4 mg/hen/day+ $200 \mathrm{mg} / \mathrm{kg}$ diet respectively); and control ( $\mathrm{n}=15)$. The birds were provided with commercial feed and water ad libitum. All treatments lasted for 7 successive days. Oxidative stress induced by DEX injections significantly reduced egg production and egg weight. Vit. E alleviated this reduction when supplemented to the stress-induced hens, compared to DEX treatment. A high level of yolk lipid oxidation was associated with oxidative stress treatment and it was reduced by Vit E supplementation. It could be concluded that supernutritional levels of Vit E (200 mg/kg diet) may contribute in enhancing laying performance and antioxidative status of laying hens under stress conditions.
\end{abstract}

Keywords: Oxidative stress, egg production, vitamin E, laying hens.

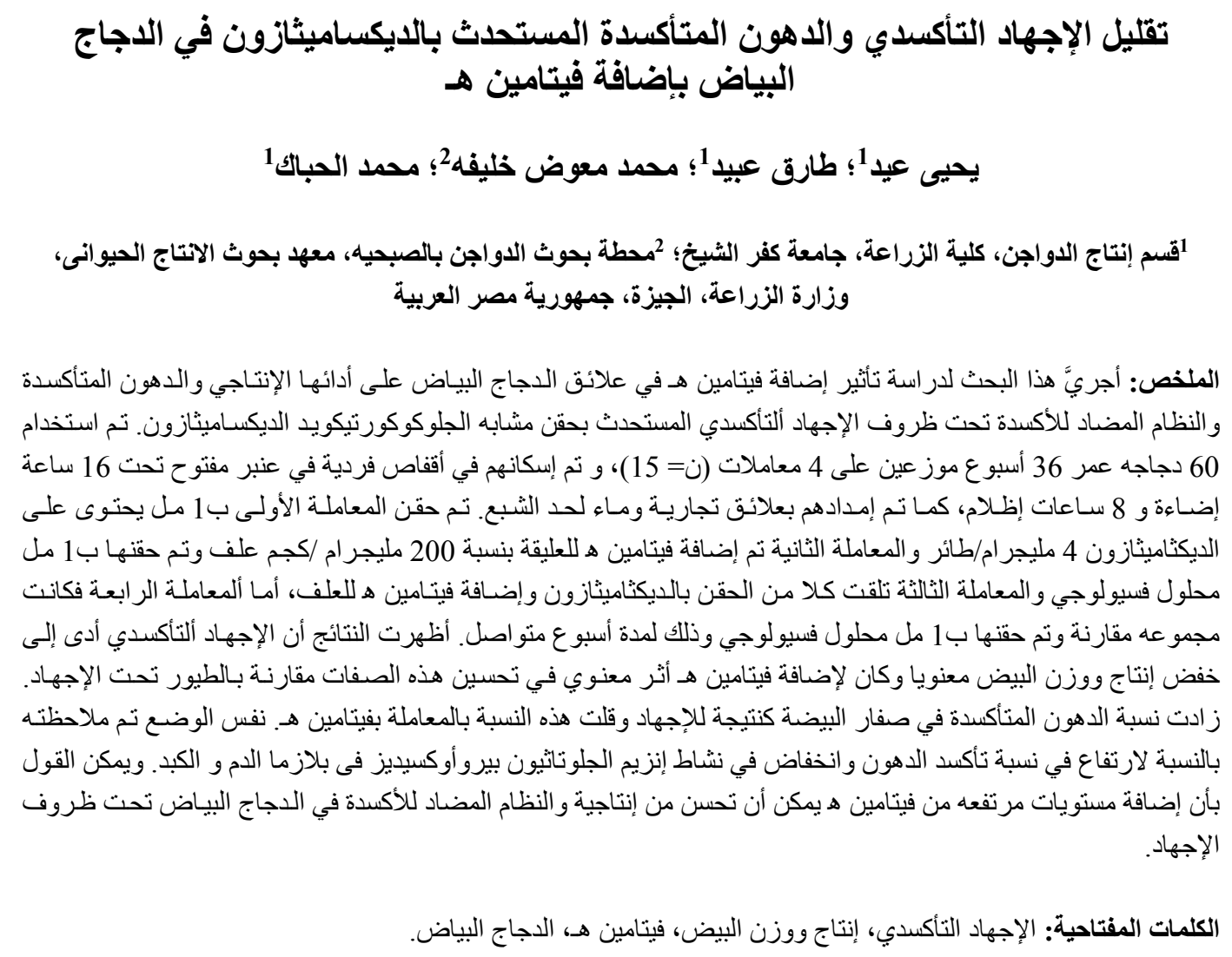




\section{Introduction}

Stress susceptibility of chickens is a major problem in the modern poultry industry. Birds are often subjected to stressors such as fasting, transport and exposure to high or low environmental temperature. During stress the endocrine system is markedly affected. The hypothalamus - pituitary - adrenal axe is seriously affected by stress (Siegel, 1980). As a result of stress, feed consumption, growth rate, feed conversion efficiency, egg quality, fertility and chick quality decline (Gross and Siegel, 1993; El-Lethey et al., 2000). In chickens, adrenal corticosteroids are secreted shortly after exposure to stress (Siegel, 1980) and elevated levels of plasma glucocorticoids have been used as an index of the response to stress in poultry (Freeman, 1971).

High levels of circulatory glucocorticoids accelerate the metabolic rates, and elevate free radical levels (in particular reactive oxygen species, ROS). ROS can have beneficial roles, as in phagocytes where they protect against bacteria and parasites. However, if natural antioxidant mechanisms are not adequate to quench excess oxygen radicals, then they can react with cell structures and attack proteins, lipids, carbohydrates and nucleotides within the cell, a state referred to as oxidative stress (Hidalgo et al., 1988). This may lead to the development of many pathological processes (Gutteridge, 1993). Enzymes that limit free-radical formation, such as glutathione peroxidase (GPX) and superoxide dismutase (SOD), play an important role in the protection of cell membranes against oxidative damage and may be used as indicators of antioxidative status.

Previous studies indicated that glucocorticoid administration induced oxidative stress status in chicken (Eid et al., 2003). Similarly, synthetic glucocorticoid dexamethasone (DEX) administration mimics the adverse effects of increased corticosterone. Dexamethasone (doses ranging from 0.2 to $4.0 \mathrm{mg} / \mathrm{kg}$ of body weight) was used as an immune suppressive agent (Fowles et al., 1993), as a mediator of prenatal stress (Welberg and Seckl, 2001; Maccari et al., 2003) and to induce oxidative stress in laying hens (El-Habbak et al., 2005) and in cockerels (Eid et al., 2006 b).

Gross and Siegel (1985) realized that the heterophil to lymphocyte $(\mathrm{H} / \mathrm{L})$ ratio could be used as an effective measure of stress in different strains of fowls. Treatment with DEX resulted in increases in white blood cell (WBC) counts, heterophil and monocytes. Also the H/L ratio was elevated by DEX treatment (Huff et al., 2001). Sahin and Kucuk (2001) declared that stress increased serum glucose, albumin, triglyceride and cholesterol and calcium concentrations. Similarly, Siegel (1995) noted that hypercholesteremia is one of many symptoms associated with long term stress.

Oxidative stress could be one of the factors negatively affecting egg quality. The oxidative stability of eggs has not been an area of major concern since their built-in antioxidant characteristics maintain the flavor during extended storage (Cuppert, 2001). However, this may be changed under stress condition due to the accelerating destruction of antioxidants to protect the birds' cells. This may lead to low oxidative stability of the eggs and reduce its quality and shelf life.

It has been suggested that antioxidants reduce the physiological response to stress in animals (Taniguchi et al., 1999; Eid et al., 2003; Eid et al., 2006 a, b). Under stressful conditions, the requirement of antioxidants such as Vit E ( $\alpha$-tocopherol) is thought to increase to protect tissues from 
lipid peroxidation (Ohtsuka et al., 1998, Eid et al., 2006 b). Vit $\mathrm{E}$ is the most efficient scavenger of peroxyl radicals in phospholipid bilayers. In the membranes of mammalian cells, Vit E scavenges lipid peroxyl radicals through hydrogen atom transfer (Chaudiea and Ferrari-Iliou, 1999). A high dietary intake of Vit E $(200 \mathrm{mg} / \mathrm{kg}$ diet) increases its concentration in both blood and seminal plasma and in addition produces beneficial changes in the antioxidant capacity and lipid profile of chicken semen (Surai et al., 1997) under normal conditions. Furthermore, use of $\alpha$ tocopherol in hen feeding seems to be an efficient way to improve the oxidative stability of eggs (Qi and Sim, 1998). Kirunda et al. (2001) have indicated some benefits of dietary vitamin $\mathrm{E}$ supplementation to laying hens during environmental stress. Oxidative damage induces a cascade of downstream reactive oxygen species, some of which are relatively transient, such as hydroxynonenol, while others appear later and accumulate, such as malondialdehyde Free radicals are neutralized by $\alpha$ tocopherol before lipid oxidation propagates among highly unsaturated fatty acids in cellular and sub-cellular membranes (Burton and Traber, 1990).

The objective of the present study is to research the effects of super-nutritional Vit E $(200 \mathrm{mg} / \mathrm{kg}$ diet $)$ supplementation on the antioxidative status and lipid peroxidation in laying hens as well as in egg yolks under oxidative stress conditions experimentally induced by DEX injections.

\section{Materials and Methods}

\section{Birds, diets and experimental design}

A total number of 60 layer hens \{Egyptian local strain (Gimmizah)\} at 36 weeks of age were selected from and approximately threefold larger population to obtain uniform body weight $(2.21 \pm 0.10$ $\mathrm{kg})$ and egg production $(82.13 \pm 1.22 \%)$. The birds were housed in individual cages and provided with water and a commercial corn-soybean diet ad libitum (16\% crude protein and metabolizable energy 2830 $\mathrm{ME} / \mathrm{Kg}, \quad 3.5 \%$ calcium, and $0.75 \%$ phosphorus). The diet was formulated to meet the recommended nutrient requirements (NRC, 1994). Ambient temperature averaged $25 \pm 2{ }^{\circ} \mathrm{C}$ with relative humidity $60-70 \%$, and a $16 \mathrm{hr}$ light: $8 \mathrm{hr}$ dark-cycle was applied. All experiments were performed in accordance with institutional guidelines concerning animal use.

The hens were divided into 4 experimental treatments $(n=15)$. The first one (DEX) was a daily intramuscular injection in the thigh of $1 \mathrm{ml}$ of the synthetic glucocorticoid Dexamethasone, DEX (as sodium phosphate $4 \mathrm{mg} / \mathrm{ml}$ ). The second treatment (Vit E) received a diet supplemented with a super-nutritional level of Vit $E$ in the form of $\alpha$-tocopherol acetate $(200 \mathrm{mg} / \mathrm{kg}$ diet $)$ and similarly injected daily intramuscularly in the femur with $1 \mathrm{ml}$ sterile physiological saline solution $(0.9 \% \mathrm{NaCl})$. The third treatment $(\mathrm{DEX}+$ Vit E) received both the DEX injection and Vit $\mathrm{E}$ supplementation $(4 \mathrm{mg} / \mathrm{hen} /$ day and $200 \mathrm{mg} / \mathrm{kg}$ diet; respectively). The fourth treatment served as control and consisted of only an intramuscular injection of the same dose of sterile physiological saline solution. All treatments lasted for 7 successive days. DEX was purchased from Amriya Pharmaceutical Industries Co., Alexandria, Egypt; meanwhile Vit E ( $\alpha$-tocopheryl acetate) was purchased from Cairo Pharmaceutical Industries Co., Egypt. 


\section{Performance parameters and sampling}

Egg production, egg weight and feed consumption were recorded daily. On the seventh day of the treatments and after 4 hours from the last injection, ten females from each treatment were randomly chosen and killed by decapitation. Liver samples were taken and kept at $-40^{\circ} \mathrm{C}$ for subsequent analysis. Blood samples were collected in heparinised tubes for blood count and other laboratory analyses. Blood smears were made and stained for differential leukocyte counts (100cells/smear; Cook, 1959) and means were calculated for heterophil and lymphocyte $(\mathrm{H} / \mathrm{L})$ ratios. Plasma was separated by centrifugation at $10,000 \mathrm{~g}$ for 10 minutes and stored at $-40{ }^{\circ} \mathrm{C}$ until analyzed.

\section{Laboratory analysis}

Glucose was estimated in the plasma according to the method of Lott and Turner (1975), by using "Glucose GOD-PAP kits" produced by Spinreact, S. A., Spain. Triglycerides were determined according to the method of Fassati and Prencipe (1983) by using "TRIGLYCERIDES kits" produced by Bio-Diagnostic Egypt. Lipid peroxidation in the blood plasma, hepatic tissues and egg yolk was measured in the form of thiobarbituric acid reactive substance (TBARS) according to the method of Richard et al. (1992). TBARS are products of the oxidative degradation of polyunsaturated fatty acids, and thus used as index of oxidative stress. Activity of the antioxidative enzyme glutathione peroxidase (GPX) was determined by the method of Levander et al. (1983). One unit of GPX activity oxidizes $1.0 \mathrm{nmol}$ of $\mathrm{NADPH} /$ (mg protein/ min). Proteins were determined in the plasma with a biuret as described by Armstrong and Carr (1964).

\section{Statistical analysis}

Differences among the experimental groups were tested by one-way ANOVA using the SPSS $^{\circledR}$ statistical software package for windows version 11.0. Duncan's multiple-range test was applied. $\mathrm{P} \leq 0.05$ was set as the limit of significance.

\section{Results}

Data describing the effect of induced oxidative stress and supplemental dietary Vitamin E on laying performance, egg weight, plasma triglycerides, plasma glucose and the $\mathrm{H} / \mathrm{L}$ ratio are presented in Table 1.

No significant differences were observed in body weight. However, there were significant differences $(\mathrm{P} \leq 0.05)$ in egg production, feed conversion and egg weight among the treatments. The worst feed conversion was detected in the DEX treatment group. However, no significant differences were found among the other experimental treatments. Induced stress via DEX administration for 7 successive days resulted in a significant decline in egg production ( $\mathrm{P} \leq 0.05$, Table 1$)$. Means of hen/day egg production were $26.5 \%$ and $71.9 \%$ in stressed and control hens respectively. It is interesting to note that supplementation of Vit $\mathrm{E}$ to the stressed birds significantly ameliorated the negative effect of DEX since egg production rose significantly (65.7\%). However, no significant difference in egg production could be detected between the Vit $\mathrm{E}$ and control birds. It is important to mention that egg production was reduced sharply on the $6^{\text {th }}$ and $7^{\text {th }}$ day of DEX administration. The same trend was observed in egg weight.

The laying hens treated for 7 successive days with DEX (4mg/bird/day) had significantly $(\mathrm{P} \leq 0.05)$ higher plasma triglycerides and glucose levels. Dietary 
Vit E significantly decreased this elevation of plasma triglycerides in the stressed and normal birds compared to the control group (Table 1). Regarding plasma glucose, there were no significant effects of dietary Vit $\mathrm{E}$ alone compared with the control. However, in case of (DEX + Vit E) treatment, Vit $\mathrm{E}$ ameliorated the negative effect of stress by decreasing the plasma glucose level compared to the DEX treatment. The Vit $\mathrm{E}$ treated birds and control birds had a significantly lower $\mathrm{H} / \mathrm{L}$ ratio compared to the DEX treatment birds (Table 1).

The influence of DEX and Vit E treatments on TBARS in egg yolk, blood plasma and liver tissues are illustrated in Figure 1. Over the course of the trial, DEX injections elevated $(\mathrm{P} \leq 0.05)$ egg yolk TBARS and Vit E supplementation appeared to partially ameliorate this effect of DEX. In the case of normal (unstressed) birds dietary Vit E alone significantly reduced yolk TBARS compared to the control (Figure 1A). Induced stress via
DEX administration significantly elevated plasma TBARS to almost 2.5 times the value in the control samples (Figure 1B). The TBARS value for the third group (DEX+Vit E) was significantly lower than that for the treatment receiving DEX alone, reaching about $54 \%$ of its value. However, it was still significantly higher than the control value. The same trend was observed in hepatic TBARS (Figure 1C), except that dietary Vit E alone significantly reduced hepatic TBARS to a level lower than the other three treatments.

The influence of DEX and Vit E treatments on hepatic GPX are graphically presented in Figure 1D. The results were completely opposite to those of TBARS. The DEX treatment caused a significant decrease of hepatic GPX activity, and supplemental Vit E ameliorated this negative effect. The DEX+Vit E treatment resulted in significantly higher values than DEX alone. Samples from the hens given supplemental Vit E alone did not significantly differ from the control.

Table 1. Effect of DEX-induced oxidative stress and dietary Vit E supplementation on performance, plasma triglycerides and glucose and $\mathrm{H} / \mathrm{L}$ ratio in laying hens. Values are expressed as means \pm standard error.

\begin{tabular}{|c|c|c|c|c|c|}
\hline & \multicolumn{4}{|c|}{ Treatment } & \multirow{2}{*}{ Significance } \\
\hline & DEX & Vit E & DEX + Vit E & Control & \\
\hline Egg Production (\%) & $26.5 \pm 3.1^{\mathbf{c}}$ & $72.1 \pm 1.5^{\mathrm{a}}$ & $55.7 \pm 2.4^{b}$ & $71.9 \pm 1.2^{\mathrm{a}}$ & $*$ \\
\hline Egg weight (g) & $44.2 \pm 1.1^{\mathbf{c}}$ & $48.9 \pm 0.9^{\mathrm{a}}$ & $46.1 \pm 1.1^{\mathbf{b}}$ & $49.4 \pm 1.2^{\mathrm{a}}$ & $*$ \\
\hline Triglycerides (mg/dl) & $455.9 \pm 10.7^{\mathrm{a}}$ & $273.4 \pm 11.4^{\mathrm{d}}$ & $381.8 \pm 10.9^{b}$ & $315.2 \pm 12.3^{\mathbf{c}}$ & $*$ \\
\hline Glucose (mg/dl) & $375.8 \pm 18.5^{\mathrm{a}}$ & $208.4 \pm 20.3^{\mathbf{c}}$ & $302.7 \pm 16.1^{\mathbf{b}}$ & $210.2 \pm 18.4^{\mathrm{c}}$ & $*$ \\
\hline $\mathrm{H} / \mathrm{L}$ ratio & $0.62 \pm 0.01^{\mathrm{a}}$ & $0.38 \pm 0.02^{\mathbf{b}}$ & $0.41 \pm 0.03^{\mathbf{b}}$ & $0.39 \pm 0.02^{\mathbf{b}}$ & $*$ \\
\hline
\end{tabular}

$\overline{\mathrm{a}, \mathrm{b}, \mathrm{c}, \mathrm{d},}$ Means within a row with no common superscript differ significantly $(P \leq 0.05){ }^{*}(\mathrm{P} \leq 0.05)$. 

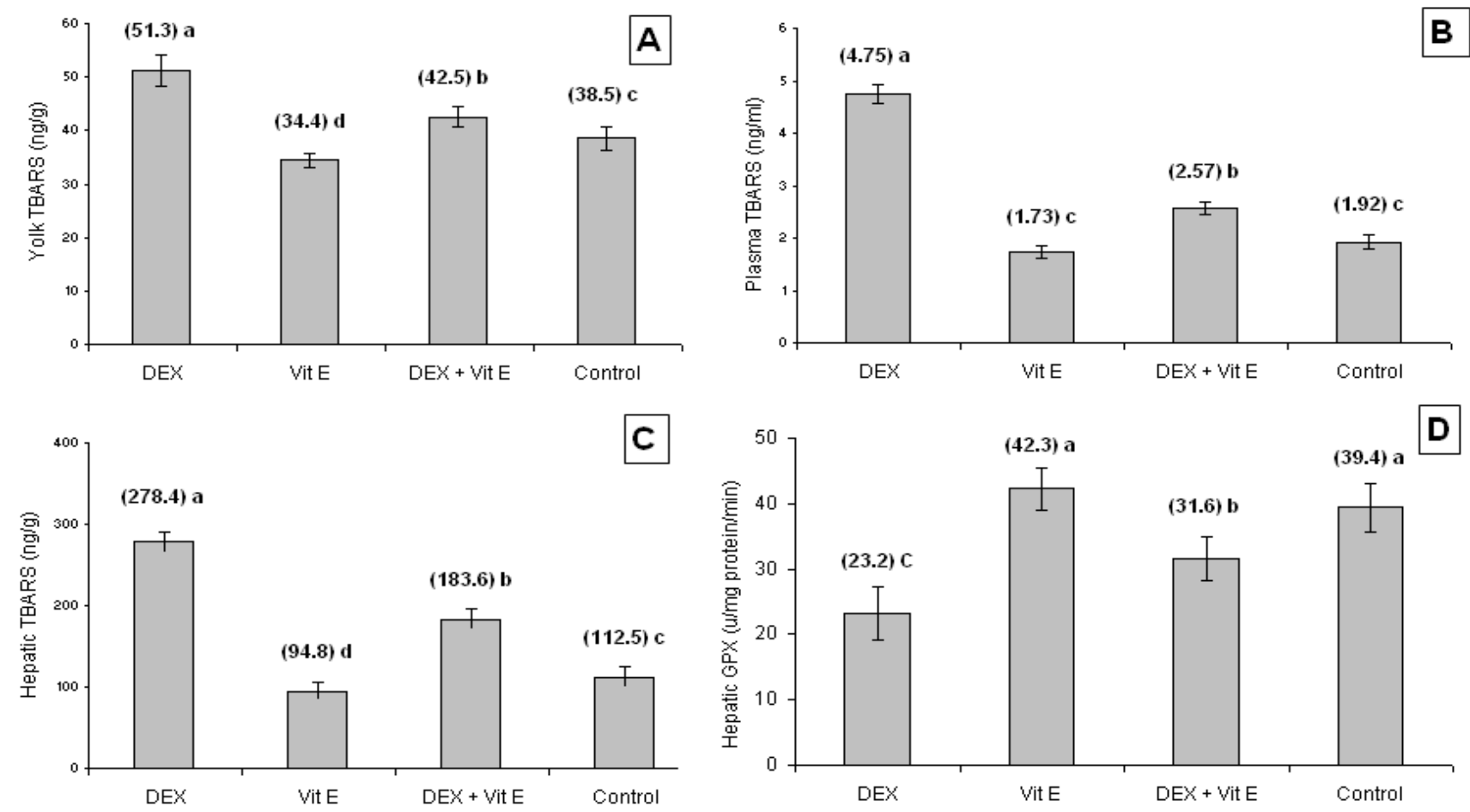

Figure 1. Effect of DEX-induced oxidative stress and dietary Vit $E$ supplementation on TBARS in (A) egg yolk, (B) blood plasma and (C) liver and GPX (D) activity in the liver of laying hens. Values are expressed as means \pm standard error; means with different script are significantly different from each other $(\mathrm{P} \leq 0.05)$.

\section{Discussion}

Induced stress by daily injection of DEX for 7 successive days caused a significant $(\mathrm{P} \leq 0.05)$ decline in egg production and egg weight (Table 1). It was observed that egg production was reduced sharply on the $6^{\text {th }}$ and $7^{\text {th }}$ day of DEX administration. These responses are in agreement with the results obtained by Siegel (1980), Hill (1983), El-Lethey et al. (2001; 2003) and El-Habbak et al. (2005). They noted that increases of circulating levels of glucocorticoids caused a reduction in egg production, delayed the onset of egg laying and also inhibited the reproduction. A possible explanation for this could be found in a report by Etches et al. (1984), who established that DEX administration or infusions of corticosterone blocked ovulation. These results were confirmed by Huang and Shirley (2001), who observed that treatment of the follicles with increasing concentrations of DEX suppressed LH and progesterone production. Similarly, Deitemeyer et al. (1985) indicated that DEX markedly inhibited the synthesis of prostaglandin E2. Dexamethasone markedly decreased inhibin production by granulosa cells in vitro, and consequently, decreased the plasma inhibin concentration (Vanmontfort et al., 1997). Inhibin, a dimeric glycoprotein, is involved in the regulation of follicular development by providing negative feedback for the secretion of pituitary follicle-stimulating hormone (FSH) (Burger, 1988). Since dexamethasone is liposoluble, it may preferentially accumulate in the yolk-filled preovulatory follicles and exert a prolonged suppressive effect on the 
production of inhibin by the surrounding granulosa layer (Decuypere et al., 1997).

Dietary Vit E under stress conditions significantly enhanced egg production and egg weight compared with the stressed group (Table 1). This may be due to the antioxidant properties of Vit E (Trader and Atkinson, 2007). Another explanation is that dietary Vit $\mathrm{E}$ may reduce the circulatory levels of glucocorticoids (Eid et al., 2003) which in turn will reduce the formation of free radicals. However, we have no data in this paper to support this point of view.

Vit E alone did not show any effect on egg production or egg weight compared with the control group. This in agreement with Grobas et al. (1997), who used two levels of Vitamin E (13 and $263 \mathrm{mg} / \mathrm{kg}$ ) and observed no difference in egg production. These results also are in agreement with the observations of Hossain et al. (1998) and Panagiota et al. (2006).

Glucocorticoid treatment results in insulin resistance, hyperglycaemia, and hypertriglyceridemia, resulting in increasing abdominal fat content and fatty liver. These symptoms are commonly seen in streptozotocin-induced diabetic mellitus (Rhee et al., 1995; Cameron-Smith et al., 1997), which is accompanied by increases in lipid peroxidation (Hidalgo et al., 1988). Our results show that plasma triglyceride concentrations in the DEX treatment were increased significantly to $144.6 \%$ of the control treatment (Table 1). Furthermore, it was shown in the present study that Vit E significantly decreased plasma triglyceride concentration in both DEX treated or untreated birds as compared to the control group. These results suggest that the antioxidants including Vit $\mathrm{E}$ play an important role in lipid metabolism of the whole body protecting lipid molecules from peroxidation by scavenging free radicals (Taniguchi et al., 1999; Eid et al., 2003, 2006 a,b).

The laying hens treated for 7 successive days with DEX (4 mg/bird/day) had significantly $(\mathrm{P} \leq 0.05)$ increased plasma glucose levels relative to the control birds (Table 1). These results are in agreement with Kobayashi et al. (1989) and El-Habbak et al. (2005), who found that DEX increased the level of plasma glucose. Moreover, Freeman et al. (1971) noted that hyperglycemia developed after 2 $\mathrm{hr}$ in birds which were injected with corticotrophin. Furthermore, a single injection of corticotrophin (Siegel and Beane, 1961) or a series of three at daily intervals (Bell, 1961) led to hyperglycemia which persisted for at least $24 \mathrm{hr}$. This elevation in plasma glucose levels is attributed to enhancing of glycogenolysis and hepatic glucose-6-phosphate (Joseph and Ramachandran, 1992). Corticosterone also induced circulating insulin (Bisbis et al., 1994). In addition, the effects may be indirect in that exogenous corticosterone produces changes in other hormones of intermediary metabolism such as thyroid hormones, growth hormone, prolactin, somatomedin C and norepinephrine (John et al., 1987; Saadoun et al., 1987).

The H/L ratio was increased by DEX administration. The data in Table 1 show that DEX injection induced a higher $\mathrm{H} / \mathrm{L}$ ratio than infusion of vehicle only (control). These observations were repeatedly reported by Huff et al. (2001) and El-Habbak et al. (2005), who noted that treatment with DEX resulted in increases in the H/L ratio. Similarly, ElLethey et al. $(2001 ; 2003)$ showed that birds fed on corticosterone had higher $\mathrm{H} / \mathrm{L}$ ratios. Moreover, the upward shift in the $\mathrm{H} / \mathrm{L}$ ratio occurs during stress (Gross and Siegel, 1993; McFarlane and Curtis, 1989). 
Moreover, Gross and Siegel $(1985,1993)$ and Al-Murrani et al. (2006) realized that the $\mathrm{H} / \mathrm{L}$ ratio could be used as an effective measure of social stress in different strains of fowls. It is noteworthy to indicate that dietary Vit E could ameliorate these increases under stress conditions. However Vit $\mathrm{E}$ alone did not have any significant effect when compared with control.

Several studies have also indicated some benefits of dietary Vit E supplementation to laying hens during environmental stress (Bollengier-Lee et al., 1999; Kirunda et al., 2001; Puthpongsiriporn et al., 2001; Kucuk et al., 2003). Due mainly to its anti-stress properties, Vit $\mathrm{E}$ alleviates negative effects of high environmental temperature stress. However, little attention was paid to the relation between Vit $\mathrm{E}$ and the antioxidative system.

By using malondiaidehyde (TBARS) as a marker of the oxidative stress, we studied the effect of induced oxidative stress and supplemental dietary Vit E on lipid oxidation in egg yolk and lipid peroxidation in plasma and hepatic tissues. TBARS is a product of the oxidative degradation of polyunsaturated fatty acids and is thus used as an index of oxidative stress. As a result of induced stress, the yolk in DEX treatment had the highest TBARS levels $(\mathrm{P} \leq 0.05)$. The elevated TBARS levels were found to be decreased by using Vit $\mathrm{E}$ either with stress or alone (Figure 1). The same trend was observed in both plasma and hepatic TBARS except that Vit $\mathrm{E}$ alone did not have any significant effect compared with the control. The effect of induced stress on plasma and hepatic TBARS are in agreement with our previous work (Eid et al., 2003; $2006 \mathrm{a}, \mathrm{b}$ ). There is a high level of TBARS in the yolk of the stressed birds, and this was correlated with high level of TBARS in both plasma and liver. This may result from the fact that the liver is the major metabolic center in the body, where yolk precursors are synthesized then transferred to the ovary. Therefore, it could be possible that the elevated level of TBARS was transferred to the yolk from the liver (Van Elswyk, 1997). This elevated yolk TBARS level may affect the shelf life of the eggs and reduce their quality. The oxidative stability of eggs has not been an area of major concern since their built-in antioxidant characteristics maintain the flavor during extended storage (Cuppert, 2001). However, this may be changed under stress conditions due to the accelerating consumption of antioxidants to protect the birds' cells. This may lead to low oxidative stability of the eggs and reduce its quality and shelf life. Because of the free radical scavenging ability of Vit $\mathrm{E}$ either under stress or alone, levels of TBARS were found to be decreased with Vit E supplementation. It could be speculated that feeding laying hens with high levels of Vit E under stress seems to be an efficient way to improve the oxidative stability of eggs; this is in agreement with (Qi and Sim, 1998).

The liver and kidney are major metabolic centers in the body and are likely organs for free radicals attacks. GPX (EC 1.11.1.19) is one of the components of the enzymatic defense system against free radicals. GPX catalyzes the reduction of a variety of hydroperoxides ( $\mathrm{ROOH}$ and $\mathrm{H}_{2} \mathrm{O}_{2}$ ) using glutathione, thereby protecting cells against oxidative damage. Nutrition and environmental factors of the animal play crucial role in normal enzyme activity (Mézes et al., 2003), so measuring such parameters may be useful in evaluating the whole body defense system. The data of the present work showed that induced stress by DEX significantly $(\mathrm{P} \leq$ 0.05 ) decreased the activity of GPX in the hepatic tissues (Figure 1). Vit E enhanced 
the activity of GPX under stress significantly $(\mathrm{P} \leq 0.05)$ compared to the stress treatment. However; Vit E alone had no significant effect compared to the control (Figure 1). There were a number of studies showing the relation between glucocorticoids and antioxidative defense systems. Dexamethasone was reported to reduce the activity of GPX (Eid, $2006 \mathrm{a}, \mathrm{b})$. This could led the speculation that Vit E may improve the antioxidative system, and this assumption agrees with Ohtsuka et al. (1998).

In conclusion, based on the previous results, it could be mentioned that the antioxidants such as Vit E play an important role under the oxidative stress conditions by decreasing lipid peroxidation level and enhancing the antioxidative defense. This could improve performance and product quality. These natural antioxidants could contribute in enhancing the welfare of the birds raised under stressful conditions. However, dietary guidelines for using supplemental antioxidants under stressful conditions should be studied. The results of this study provide suggestions for egg production under stressful conditions. This is especially important because consumers are now more concerned about the quality and nutritive value of foods.

\section{References}

Al-Murrani, W. K., A. J. Al-Rawi, M. F. Al- Hadithi and B. Al-Tikriti. 2006. Association between heterophil/lymphocyte ratio, a marker of 'resistance' to stress, and some production and fitness traits in chickens. British Poultry Science 47:443- 448.

Armstrong, W. D. and C. W. Carr. 1964.
Physiological Chemistry Laboratory Directions (3rd Edn.) Burgess, Minneapolis, MN.

Bell, D. J. 1961. Adrenocorticotropin and the sugar level in plasma in young fowls. Nature 190:913.

Bisbis, S., M. Taouis, M. Derouet, B.Chevalier and J. Simon. 1994. Corticosterone-induced insulin resistance is not associated with alterations of insulin receptor number and kinase activity in chicken kidney. General and Comparative Endocrinology 96:370-377.

Bollengier-Lee, S., P. E. V. Williams and C.C. Whitehead. 1999. Optimal dietary concentration of vitamin $\mathrm{E}$ for alleviating the effect of heat stress on egg production in laying hens. British Poultry Science 40:102-107.

Burger, H. G.. 1988. Inhibin: definition and nomenclature, including related substances. Endocrinology 117:159160.

Burton, G. W. and M. G. Traber. 1990. Vitamin E: Antioxidant activity, biokinetics, and bioavailability. Annual Review of Nutrition 10:357.

Cameron-Smith, D., R. Habito, M. Barnett and G.R. Collier. 1997. Dietary guar gum improves insulin sensitivity in streptozotocin-induced diabetic rats. Journal of Nutrition 127:359-364.

Chaudiea, J. R. E. and R. Ferrari-Iliou. 1999. Intracellular antioxidants: from chemical to biochemical mechanisms. Food and Chemical Toxicology 37: 949-962. 
Cook, F. W. 1959. Staining fixed preparation of chicken blood cells with combinations of May-Gru"nwaldWright-Phyloxine B stain. Avian Disease 3:272-290.

Cuppert, S. L. 2001. The Use of Natural Antioxidants in Food Products of Animal Origin. In: Pokorny, J., N. Yanishlieva and M. Gordon M (Eds.). Antioxidants in Food. Woodhead Publishing Ltd. pp. 302. Cambridge, England.

Decuypere, E., L. Rombauts, D. Vanmontfort and G. Verhoeven. 1997. Inhibin from embryo to adult hen. In: Havey, S. and R. J. Etches (Eds.) Perspective in Avian Endocrinology. Journal of Endocrinology. Bristol, UK.

Deitemeyer, D., R. L. Yunker, M. Ashraf and M.T. Subbiah. 1985. Effect of glucocorticoid administration early in life on aortic prostaglandin synthesis and morphology in atherosclerosissusceptible pigeons. Experimental and Clinical Endocrinology 85:147-154.

Eid, Y. Z., T. A. Ebeid, A. Ohtsuka and K. Hayashi. 2006a. Using Un Traditional Sources of Antioxidants to Cope with Stress in Broiler Chickens. pp. 199 204. In: Yahav, S. and B. Tzschentke (Eds.) New Insights into fundamental physiology and peri-natal adaptation of domestic fowl. Nottingham University Press, Nottingham, UK.

Eid, Y., T. Ebeid and H. Younis. 2006b. Vitamin E Supplementation Reduces Dexamethasone-Induced Oxidative Stress in Chicken Semen. British Poultry Science 47:350 - 356.
Eid, Y., A. Ohtsuka and K. Hayashi. 2003. Tea polyphenols reduce glucocorticoid induced growth inhibition and oxidative stress in broiler chickens. British Poultry Science 44:127-132.

EL-Habbak, M. M., S. B. Abou-EL-Soud and T.A.Ebeid. 2005. Effect of induced stress by dexamethasone administration on performance, egg quality and some blood parameters of laying hens. Egyptian Poultry Science 25:89-105.

EL-Lethey, A. H., V. Jungi and T. B. Wechsler. 2000. Stress and feather pecking in laying hens in relation to housing conditions. British Poultry Science 41:22-28.

El-Lethey, H., B. Huber-Eicher and T. W. Jungi. 2003. Exploration of stressinduced immunosuppression in chickens reveals both stress-resistant and stress-susceptible antigen responses. Veterinary Immunology and Immunopathology 95:91-101.

El-lethey, H., T. W. Jungi and B. HuberEicher. 2001. Effects of feeding corticosterone and housing conditions on feather pecking in laying hens (Gallus domesticus). Physiological Behavior 73:243-251.

Etches R. J., J. N. Petitte and C. E. Anderson-Langmuir. 1984. Interrelationships between the hypothalamus, pituitary gland, ovary, adrenal gland, and the open period for LH release in the hen (Gallus domesticus). Journal of Experimental Zoology 232:501-511.

Fassati, P., L. Prencipe and D. Berli. 1983. Enzymic creatimne assay: a new 
colorimetric method based on hydrogen peroxide measurement. Clinical Chemistry 28:1494-6.

Fowles, J. R., A. Fairbrother, M. Fix, S. Schiller and N.I. Kerkvliet. 1993. Glucocorticoid effects on natural and humoral immunity in mallards. Developmental Comparative Immunology 17:165-177.

Freeman, B. M. 1971. Stress and domestic fowl: a physiological appraisal. World's Poultry Science Journal 27: 263-275.

Grobas, S., J. Mendez, C. de Blas and G. G. Matoes. 1997. Influence of dietary vitamins $\mathrm{E}$ and $\mathrm{A}$ on performance, egg quality and $\alpha$-tocopherol content of yolks. Poultry Science, 76 (Suppl. 1):371 (Abstr.).

Gross, W. B.; Siegel, P. B., 1985: Selective breeding of chickens for corticosterone response to social stress. Poultry Science 64:2230-2233.

Gross, W. B. and P. B. Siegel. 1993. General principles of stress and welfare. In: Grandin, T. (Ed.). pp. 2133. Livestock Handling and Transport, $\mathrm{CAB}$ International, Wallingford.

Gutteridge, J. M. C. 1993. Free radicals in disease processes: a compilation of cause and consequence. Free Radical Research Communications 19:141158.

Hidalgo, J., L. Campmany, M. Borras, J. S. Garvey and A. Armario. 1988. Metallothionein response to stress in rats: role in free radical scavenging.
American Journal of Physiology 255:E518-E524.

Hill, J. A. 1983. Indicators of stress in poultry. World's Poultry Science Journal 39:24-31.

Hossain, S. M., S. L. Barretoa, A. G. Bertechinib, A. M. Riosa and C. G. Silvaa. 1998. Influence of dietary Vitamin E level on egg production of broiler breeders, and on the growth and immune response of progeny in comparison with the progeny from eggs injected with Vitamin E. Animal Feed Science and Technology 73:307317.

Huang, T. J. and L. P. Shirley. 2001. Dexamethasone inhibits luteinizing hormone-induced synthesis of steroidogenic acute regulatory protein in cultured rat preovulatory follicles. Biology of Reproduction 64:163-170.

Huff, G. R., W. E. Huff, J. M. Balog and N. C. Rath. 2001. Effect of early handling of turkey poults on later responses to a dexamethasoneEscherichia coli challenge. 1. Production values and physiological response. Poultry Science 80:13051313.

John, T.M., M. Viswanathan, R. J. Etches, B. Pilo and J. C. George. 1987. Influence of corticosterone infusion on plasma levels of catecholamines, thyroid hormones and certain metabolites in laying hens. Poultry Science 66:1059-1063.

Joseph, J. and A. V. Ramachandran. 1992. Alterations in carbohydrate metabolism by exogenous 
dexamethasone and corticosterone in post-hatched White Leghorn chicks. British Poultry Science 33:1085-1093.

Kirunda, D. F. K., S. E. Scheideler and

S. R. McKee. 2001. The efficacy of vitamin E (DL- $\alpha$-tocopheryl acetate) supplementation in hen diets to alleviate egg quality deterioration associated with high temperature exposure. Poultry Science 80:13781384.

Kobayashi, T., H. Iwai, R. Uchimoto, M. Ohta, M. Shiota and T. Sugano. 1989. Gluconeogenesis in perfused livers from dexamethasone-treated chickens. American Journal of Physiology 256:907-14.

Kucuk, O., N. Sahin, M.F. Gursu, F. Gulcu, M. Ozcelik and M. Issi. 2003. Egg production, egg quality, and lipid peroxidation status in laying hens maintained at a low ambient temperature $\left(6^{\circ} \mathrm{C}\right)$ and fed a vitamin $\mathrm{C}$ and vitamin E-supplemented diet. Veterinarni Medicina 48:1-2, 33-40.

Levander, O. A., D. P. Deloach, V. C. Morris and P. B. Moser. 1983. Platelet glutathione peroxidase activity as an index of selenium status in rats. Journal of Nutrition 113:55-63.

Lott, J., K. Turner. 1975. Evaluation of Trinder's glucose oxidase method for measuring glucose in serum and urine. Clinical Chemistry 21:1754-1760.

Maccari, S., M. Darnaudery, S. MorleyFletcher, A.R. Zuena, C. Cinque and O. Van Reeth. 2003. Prenatal stress and long-term consequences: implications of glucocorticoids hormones. Neuroscience Biobehavior
Reviews 27:119-127.

McFarlane, J. M. and S. E. Curtis. 1989. Multiple concurrent stressors in chicks. 3. Effects on plasma corticosterone and heterophil: lymphocyte ratio. Poultry Science 68:522-527.

Mézes, M., M. Erdélyi, G. Shaaban, G. Vir, K. Balogh and M. Wéber. 2003. Genetics of glutathione peroxidase. Acta Biologica Szegediensis 47:135138.

NRC (National Research Council) 1994. Nutrient requirement of domestic animals. In: Nutrient Requirements of Poultry, 9th rev. ed. National Academic Press, Washington D.C.

Ohtsuka, A., T. Ohtani, H. Horiguchi, H. Kojima and K. Hayashi. 1998. Vitamin E reduces glucocorticoidinduced growth inhibition and lipid peroxidation in rats. Journal of Nutritional Science and Vitaminology 44:237-247.

Panagiota, F. P., D. Dimitrios, M. Ioannis, D. Vassilios, B. Evropi, N. Ioannis and B. Nikolaos. 2006. Effect of feeding rosemary and $\alpha$-tocopheryl acetate on hen performance and egg quality. The Journal of Poultry Science 43:143-149.

Puthpongsiriporn, U., S. E. Scheideler, J. L. Sell and M.M. Beck. 2001. Effects of vitamin $\mathrm{E}$ and $\mathrm{C}$ supplementation on performance, in vitro lymphocyte proliferation, and antioxidant status of laying hens during heat stress. Poultry Science 80:1190-1200.

Qi, G. H. and J. S. Sim. 1998. Natural tocopherol enrichment and its effect in 
n-3 fatty acid modified chicken eggs. Journal of Agriculture and Food Chemistry 46:1920-1926.

Rhee, S. J., W. K. Choe and T. Y. Ha. 1995. The effect of vitamin $E$ on the antioxidative defense mechanism in streptozotocin-induced diabetic rats. Nippon Eiyo Shokuryou Gakkaishi (Journal of Japanese Society of Nutrition and Food Science) 48:451457.

Richard, M. J., B. Portal, J. Meo, C. Coudray, A. Hadjian and A. Favier. 1992. Malondialdehyde kit evaluated for determining plasma and lipoprotein fractions that react with thiobarbituric acid. Clinical Chemistry 38:704-709.

Saadoun, A., J. Simon and B. Leclercq. 1987. Effect of exogenous corticosterone in genetically fat and lean chickens. British Poultry Science 28:519-528.

Sahin, K. and O. Kucuk. 2001. A simple way to reduce heat stress in laying hens as judged by egg laying, body weight gain and biochemical parameters. Acta Veterinaria Hungarica 49:421-430.

Siegel, H. S. 1980. Physiological stress in birds. Bioscience 30:529-534.

Siegel, H. S. 1995. Stress, strains and resistance. British Poultry Science 36:3-22.

Siegel, H. S. and W. L. Beane. 1961. Time responses to single intramuscular doses of ACTH. Poultry Science 40:216-219.
SPSS Statistical Packages for the Social Sciences. 2001. Statistical software for windows version 11.0 Microsoft. SPSS $^{\circledR}$, Chicago, IL, USA.

Surai, P. F., E. Kutz, G. J. Wishart, R. C. Noble and B. K. Speake. 1997. The relationship between the dietary provision of alpha-tocopherol and the concentration of this vitamin in the semen of chicken: effects on lipid composition and susceptibility to peroxidation. Journal of Reproduction and Fertility 110:47-51.

Taniguchi, N., A. Ohtsuka and K. Hayashi. 1999. Effect of dietary corticosterone and vitamin $\mathrm{E}$ on growth and oxidative stress in broiler chickens. Animal Science Journal 70:195-200.

Trader, M. G. and J. Atkinson. 2007. Vitamin E, antioxidant and nothing more. Free Radical Biology Medicine. doi:10.1016/j.freeradbiomed.2007.03.0 24

Van Elswyk, M. E. 1997. Nutritional and physiological effects of flax seed in diets for laying fowl. World's Poultry Science Journal 53:253-264

Vanmontfort, D., G. Room, V. Bruggeman, L. Rombauts, L.R. Berghman, G. Verhoeven and E. Decuypere. 1997. Ovarian and extra-ovarian sources of immunoreactive Inhibin in the chicken: effects of dexamethasone. General and Comparative Endocrinology 105:333-343.

Welberg, L. A. and J. R. Seckl. 2001. Prenatal stress, glucocorticoids and the programming of the brain. Journal of Neuroendocrinology 13:113-128. 